\title{
EDUCAÇÃO E TECNOLOGIAS DA COMUNICAÇÃO
}

\section{EDUCATION AND COMMUNICATION TECHNOLOGIES}

\author{
Adair Adams \\ Instituto Federal de Educação e Tecnologia do Rio Grande do Sul, Vacaria, RS, Brasil. E-mail: adair. \\ adams@vacaria.ifrs.edu.br \\ https://orcid.org/0000-0003-1689-2691
}

DOI: https://doi.org/10.46550/amormundi.v1i1.8

Recebido em: 15.09.2020

Aceito em: 20.10.2020

\begin{abstract}
Resumo: Pensar a educação a partir da configuração antropológica do presente, constituída pela época comunicacional condicionada pelas mídias e tecnologias da comunicação, é o objeto deste texto. Compreendo que o pressuposto mais geral da pedagogia é a antropologia, pois é preciso saber quem é o homem, sempre no presente, para que possamos pensar as necessidades e possibilidades da educaçáo, também, sempre no presente. A partir de referências bibliográficas atuais sobre o tema em diálogo com autores da tradição filosófica sobre a técnica, proponho uma revisão da ideia, quase consensual, de que as novas tecnologias são o lugar de fala da educação atual. $\mathrm{O}$ horizonte é um questionamento e a demonstração de possíveis equívocos na argumentaçáo que insere as novas geraçóes na categoria de "novos digitais".
\end{abstract}

Palavras-chave: Educação. Antropologia. Comunicação. Tecnologias.

Abstract: Thinking about education from the anthropological configuration of the present, constituted by the communicational age conditioned by the media and communication technologies, is the object of this text. I understand that the most general premise of pedagogy is anthropology, as it is necessary to know who man is, always in the present, so that we can think about the needs and possibilities of education, too, always in the present. Based on current bibliographic references on the topic in dialogue with authors of the philosophical tradition about the technique, I propose a revision of the idea, almost consensual, that new technologies are the place of speech of current education. The horizon is a questioning and the demonstration of possible mistakes in the argument that inserts the new generations in the category of "new digital".

Keywords: Education. Anthropology. Communication. Technologies.

\section{Consideraçóes iniciais}

$\Delta$ antropologia atual poderia ser pensada sob o conceito de homo comunicator. Entendo Aque o modo de ser e viver, a linguagem, a compreensão e organização do mundo, como totalidade da existência, tem como elemento organizador o analógico-dialógico-virtual. Também, os meios de comunicação, em todas as formas de tecnologias, constituem o modo de ser e viver do ser humano. É nos modos de ser e viver que se manifesta o que e quem é o ser 
humano.

$\mathrm{Na}$ educação, esse modo de ser tornou-se um elemento central e ao mesmo tempo desafiador. Pois, não está apenas na metodologia nem no conteúdo a questão mais desafiadora, mas, no como construir relaçóes entre os envolvidos para que conhecimentos sejam constituídos e significados. Os educandos que chegam às escolas situam-se num horizonte de compreensão antropológico tecno-midiáticos. Procuro pensar a partir de Gilles Lipovetsky, mostrando um vazio, vivido no e pelo "individualismo contemporâneo" (2005, p. 20), constituído na educação com toda essa revolução tecno-midiática, descrita por Pierre Levy (1999), como uma época de mundo ciber. Esse novo enraizamento antropológico requer uma compreensão elaborada de suas dimensôes e manifestaçóes para poder pensar a educação no atual mundo vivido. Essa questão é analisada a partir da obra de Muniz de Sodré, que propóe a escola como uma linguagem, como um lugar por excelência de uma ética em que os assuntos e temas precisam ser pensados, definidos e organizados coletivamente, que tem nos meios de comunicação e suas tecnologias o seu centro vital, o elemento organizador da vida da educação. Tenciono também a discussão, a partir da obra de Pierre Levy, que procura mostrar as novas relaçóes educacionais dentro da configuração societal ciber, sobretudo, a importância da educação como cultura para que o diálogo analógico-digital e virtual não seja marcado por um vazio humano, mas de reflexão ética entre as diversas áreas de conhecimento.

$\mathrm{O}$ artigo propõe analisar a configuração antropológica atual e, consequentemente, educacional na perspectiva de "escolarizar a máquina" e não "maquinar a escola". O argumento central do texto é pensar uma educação em e com seres humanos tecno-midiáticos sob o horizonte da escola, da educação, e não das tecnologias, para pensar novas relações éticas, de relações sociais e culturais e políticas. Pois, é a ética, como reflexão interdisciplinar que precisa ser o elemento organizador da vida da escola e não uma disciplina concretizada em tecnologia subjugar todas as outras áreas. A questão não é simplesmente do que a escola vai fazer com as novas tecnologias, nem o que as novas tecnologias vão fazer com a escola. Mas o que a escola vai fazer com aquilo que as novas tecnologias estão fazendo dela.

Toda a argumentação apresentada neste texto é resultado de uma pesquisa bibliográfica. Os autores utilizados para as reflexôes são essencialmente da filosofia e sociologia, tanto contemporâneos que buscam realizar uma leitura do presente quanto da tradição do início do século vinte. A arguição busca pensar a partir e com os autores e suas implicações na educação.

\section{Argumentação}

Ser e estar com as tecno-mídias é o modo de ser mais fundamental da antropologia atual dos educandos na qual os educadores estão envolvidos direta e indiretamente. No entanto, é preciso compreender o que isso significa em termos propriamente humanos e em termos de mercado e economia. Para Sodré (2006), o mercado soube trabalhar eficazmente com os desejos, as sensaçóes, as vontades, as necessidades, as angústias, esperanças e problemas que envolvem o viver humano na época atual. Os avanços tecnológicos estiveram sempre coimplicados com um saber sobre o ser humano e formas de comercializar esse viver. Nesse processo de configuração do vital, consciência, identidade, subjetividade, ética, cultura, educação, política, economia, valores, sentimentos, processos cognitivos, objetos, são compreendidos num ethos midiatizado. 
Compreendo que a antropologia é um pressuposto básico da educação. A antropologia compreendida dentro da nova configuração da sociedade, como base para pensar uma educação que “incorpore as neo-tecnologias analógico-digitalistas" (SODRÉ, 2002, p. 114), sem se tornar um produto do mercado e da economia globalizada, fazendo do ser humano um espelho das relaçóes de troca e venda de produtos. Toda essa transformação societal gerou um vazio de valores, crenças, acordos, consensos, interpretaçóes, verdades, conhecimentos, onde o vazio como uma época que vivemos, segundo Lipovetsky. É esse vazio, que proponho pensar, na perspectiva da educação. Impóe-se lembrar, que não se pode perder a dimensão escolar da transmissão/recontextualizaçãol mediação não só de conhecimentos, mas de condiçōes de possibilidade de interpretação e compreensão de si, dos outros e do mundo em suas relaçôes e organizaçôes. Outrossim, a educação "implica primeiramente comunicar, o que significa implementar um laço atrativo, a partir de um quadro comum de referências estabelecido por uma cultura histórica, isto é, por toda uma tradição de costumes, saberes e valores um ethos, objeto da hexis instauradora da consciência ética. Depois a educação comporta um diálogo necessário entre a produção do saber e o mundo do trabalho" (SODRÉ, 2002, p. 114).

Os processos e relaçōes das tecnologias precisam estar a serviço da educação e não a educação a serviço das tecnologias midiáticas e de informação. Mas essa compreensão tem seu viés na e pela incorporação vivencial as tecno-mídias e não numa posição de aversão ou de crítica simplesmente. Trata-se de estabelecer uma posiçáo educacional frente ao discurso da economia e do mercado enquanto determinante das tecno-mídias. Com essa posição educacional que vive o homo comunicator, é possível pensar os novos excluídos, nas mazelas da sociedade, a democracia, a política a ética, como uma nova forma de emancipação por uma intersubjetividade praticamente digital.

Este breve estudo sobre novas relaçóes na educaçáo da neomodernidade se processa por uma via pró-ativa em relação a nova configuração antropológica e societal com as mídias e suas tecnologias, evocando a argumentação de Muniz de Sodré que afirma a urgência de uma escolarização da máquina e da imprescindibilidade da educaçáo como cultura na base de toda a evolução das tecno-mídias. Essa rede relacional neomoderna da educação desenvolvo em quatro pontos:

O primeiro ponto é o entendido da sociedade como analógica-digital condicionante das novas relaçóes de vida. Pierre Levy (1999), tem se dedicado a compreender as novas configuraçôes da sociedade atual a partir da revolução da comunicação e suas tecnologias. As novas geraçóes, sobretudo, da geração escolar atual vivem um mundo digital, organizando suas relaçôes, seus afazeres, sua vida de modo geral a partir da infra-estrutura técnica da virtualização. A comunicação, o diálogo, a intersubjetividade tem como pressuposto essa nova configuração de uma geração que tem como modo de ser analógico-digital. Não apenas "ciberespaço", mas cibertempo e, nestes, o condicionamento das relaçôes humanas. Essa infra-estrutura relacional atinge em cheio a forma e o ser da educação contemporânea.

A educação já não pode mais ter uma configuração que não contemple de modo fulcral e efetivo essa revolução tecno-comunicativa. $\mathrm{O}$ que procuro defender é que não se trata de fazer da escola um grande laboratório de informática ou de outra tecnologia, mas "sim de acompanhar consciente e deliberadamente uma mudança de civilização que questiona profundamente as formas institucionais, as mentalidades e a cultura dos sistemas educacionais tradicionais e, sobretudo, os 
papéis de professor e aluno" (LEVY, 1999, p. 172). Não se trata de criar um novo papel ou uma nova função para a escola, mas de reorganizá-la, no sentido de que a escola precisa cumprir sua função democratizante de criar pertencimento à humanidade por parte dos educandos.

A educação não pode estar a mercê de tecnologias que sejam compreendidas como novas metodologias de ensino. Os seus usos são possíveis a partir do momento, segundo Boufleuer (conversas 2011), quando o professor já escreveu sua aula. O conhecimento dos educandos na utilização de tecnologias não pode ser comparado ao saber dos professores, em sentido de prioridade de um sobre outro. Isso seria uma absolutização da opiniáo, em que os conhecimentos das crianças teriam a mesma validade que o conhecimento, em seu conteúdo, sua dimensão de vida e operacionalização ética, trabalhado e ensinado pelo professor. Mesmo considerando que as informaçóes que as tecnologias nos permitem acessar sejam o mundo da vida, a educação escolar é quem tem a função de abstrair, operar conceitualmente, sobre este mundo da vida.

Para Levy (1999), essa transformação tem na forma de ser e de viver ciber da época atual sua força motriz. Trata-se de uma mudança de educação e formaçáo localizadas espacialmente e temporalmente pela escola como instituição para uma escola que é contexto, linguagem, móvel e até mesmo líquida, com nova relação de valores e organização da vida. Dentro dessa rede relacional o poder público tem uma função política primordial:

[...] - garantir a todos uma formação elementar de qualidade; - permitir a todos um acesso aberto e gratuito a midiatecas, a centros de orientação, de documentação e de autoformação, a pontos de entra no ciberespaço, sem negligenciar a indispensável mediação humana do acesso ao conhecimento; - regular e animar uma nova economia do conhecimento na qual cada indivíduo, cada grupo, cada organização seriam considerados como recursos de aprendizagem potenciais ao serviço de percursos de formação contínuos e personalizados" (LEVY, 1999, p. 172-173).

O segundo ponto é a interpretação do presente que tem no "vazio" um princípio epocal. "De agora em diante, o self- service e o atendimento à La carte designam o modelo geral da vida nas sociedades contemporâneas que vêem proliferar de modo vertiginoso as fontes de informação, abrindo-se cada vez mais o leque de produtos expostos nos centros comerciais e nos hipermercados tentaculares, nas lojas ou restaurantes especializados. Assim, a sociedade pósmoderna se caracteriza por uma tendência global a reduzir as atitudes autoritárias e dirigistas e, ao mesmo tempo, a aumentar a oportunidade de escolhas particulares, a privilegiar a diversidade e, desde já, a oferecer fórmulas e 'programas independentes' nos esportes, nas tecnologias psicanalíticas, no turismo, na moda causal, nas relaçóes humanas e sexuais" (LIPOVETSKY, 2005, p. XIII).

Para Lipovetsky, o presente atingiu uma segunda revolução individualista na história da cultura ocidental. Com ela, eliminaram-se as teleologias das proposiçóes revolucionárias, constituindo uma revolução constante do indivíduo em sua cotidianidade: "privatização ampliada, erosão das identidades sociais, desgaste ideológico e político, desestabilização acelerada das personalidades" (LIPOVETSKY, 2005, p. XV). Esse vazio vai sendo preenchido por formas de ser dos seres humanos nos e pelos meios de comunicação e suas tecnologias. Com isso surgem novas formas de ser, orientadas pela sedução, desejo, simulação, narcisismo, humorismo, espetáculo.

Nessa rede de relaçóes o individualismo à La carte, "hedonista e psicológico" 
(LIPOVETSKY, 2005, p. 190) que faz da realização da intimidade de cada um como uma finalidade essencial e quase exclusiva da existência. Nessa configuração societal a educação não consegue ser ativa na organização das dimensōes e relaçôes da sociedade. Onde impera essa forma de individualismo, a educação não tem vez. A educação é intersubjetividade dialógica, uma linguagem, uma cultura. Ela é justamente a superação do individualismo para que uma ética e política justa possa vigorar.

O vazio do presente não significa uma ausência total de sentido. É uma época de transição, para afirmar com Nietzsche, uma transvaloração de todos os valores (NIETSZCHE, 2000, p. 53) em todas as relaçôes e organizaçoóes da sociedade. Não é apenas uma época de mudança mas uma mudança e época, uma mudança de era.

Para Bauman, o presente é entendido como era do líquido. Todas as dimensóes e relaçôes da sociedade estão liquidas.

Numa sociedade líquido-moderna, as realizaçóes individuais não podem solidificar-se em posses permanentes porque, em um piscar de olhos, os ativos se transformam em passivos, e as capacidades, em incapacidades. As condiçốes de ação e as estratégias de reação envelhecem rapidamente e se tornam obsoletas antes de os atores terem uma chance de aprendê-las efetivamente. Por essa razão, aprender com a experiência a fim de se basear em estratégias e movimentos táticos empregados com sucesso no passado é pouco recomendável: testes anteriores não podem dar conta das rápidas e quase sempre imprevistas (talvez imprevisíveis) mudanças de circunstâncias. Prever tendências futuras a partir de eventos passados torna-se cada dia mais arriscado e, frequentemente, enganoso. É cada vez mais difícil fazer cálculos exatos, uma vez que os prognósticos seguros são inimagináveis: a maioria das variáveis das equaçoos (se não todas) é desconhecida, e nenhuma estimativa de suas possíveis tendências pode ser considerada plena e verdadeiramente confiável (BAUMAN, 2005, p. 5).

Esse modo de fluidez e liquidez que constitui o presente está solidificando, tornando sólido algumas formas de organização societal. Liquefazer uma forma de ser e organizar para solidificar outras. Esvaziar uma forma de ser e organizar para preencher com outras. É uma mudança de época. É para essa questáo que o artigo aponta como orientação e busca fundamental: a educação ser ativa no processo de "preenchimento", de configuração da nova ordem de valoração e sentido e de "solidificação" da sociedade. A economia de mercado, informatizada e globalizada, saiu na frente.

Encontro nessa questão uma dimensão da crise de finalidade da educação e uma parte de preenchimento desse vazio de finalidade. Com isso, revela-se um horizonte diante da atestaçáo de Savater, sobre a crise da educação: "No proviene de la deficiente forma em que la educación cumple con los objetvos sociales que tiene asignados, sino que, más grave aún, no sabemos qué finalidades debe cumplir e hacia donde efectivamente orientar sus acciones" (1997, p. 7).

O desafio central da educação, na construção de uma nova configuração de valores sociais e culturais e relações políticas e humanas é: para que meios e tecnologias de comunicação tâo potentes, imensos e poderosos para seres humanos tão pequenos, frágeis e incapazes? Incapazes de compreender a si, aos outros e ao mundo. Incapazes de valorizar a natureza, os seres humanos independente da raça, credo e etnia.

O terceiro ponto procura pensar escolarização da máquina e não maquinação da escola que está em curso. Tornou-se uma questão de inclusão social e cultural, a implantação 
de laboratórios de informática e internet em favelas e comunidades carentes. Não há dúvidas que é um processo que precisa ser ampliado no contexto atual. Mas a forma como está sendo feita é problemática. Os que têm acesso não dispóem uma formação prévia, um conhecimento cultural e social, capacidades de consciência crítica e de julgamento, capacidades de manuseio e aproveitamento das ferramentas disponibilizadas. Essa questão é peremptoriamente enfatizada por Pierre Lévy (1999) e Muniz Sodré (2002). E, não apenas em espaços de inclusão, mas no próprio âmbito da escola em geral.

Segundo Sodré (2002), as máquinas, as ferramentas, os meios, os dispositivos, sem uma inteligência de qualidade de uso podem ter um efeito negativo ou serem obsoletos para os fins a que estão dispostos. A educação atrofia seus sonhos, utopias para assumir outra utopia, que é da tecnologia, no momento que efetiva uma maquinação da escola sem um trabalho prévio de escolarização da máquina.

Esse diferencial precisa ser efetivamente assumido para que a educação não se perca no oceano das invençóes e da fluidez das relaçôes, condicionada por organizaçóes societais com outras faces, mas que concretizam uma realidade que a própria educação sempre combateu. O mundo vivido das tecno-mídias não pode passar despercebido pela educação e nem ser incorporado sem compreensão.

Os educandos são condicionados pelas tecno-midías pela dimensão da sedução. Maffesoli (1998) compreende a atualidade como uma razáo sensível, a sensibilidade como modo de ser mais característico do ser humano. Segundo Sodré (2006, p. 17), "parece que é justamente no campo do sentir que a nossa época exerceu o seu poder". Com esse argumento, é possível pensar a atualidade como "uma época estética: não por ter uma relação privilegiada e direta com as artes, mas essencialmente porque o seu campo estratégico não é o cognitivo, nem o prático, mas o do sentir, o da aisthesis" (SODRÉ, 2006, p. 17).

Vale assinalar que, nessa ordem dos fenômenos humanos, onde tem primado o sensivel ou a sensibilidade (entendida como propriedade de acolher impressóes e excitaçôes, a elas reagindo com operaçóes distintas dos processos intelectuais), os conceitos revelam-se particularmente imprecisos, a despeito do empenho tradicional da disciplina filosófica e, depois, da psicologia, da psicossociologia e da psicanálise (SODRÉ, 2006, p. 27).

Não obstante ser a sedução o elemento central da condição humana, e que Lipovetsky chama também de sexdução, a racionalidade não é negada, mas pensada de outra forma. A questão não é, simplesmente, dois tipos de racionalidade, mas de ser humano que está na base de cada uma dessas formas. O grande desafio atual é a sedução pela educação. Mas uma sedução que não seja do sistema atual da economia e de mercado, que tende a se instaurar na própria educação com a maquinação da escola. Para Milton Santos, nesse sistema de mercado não é possível integrar todos. A desintegração do sistema é a possibilidade de mudança.

A questáo da educação é ser promotora de uma cultura da educação na configuração da sociedade atual. Não existem atores educacionais sem cultura da educação e nem cultura da educação sem atores educacionais.

O diferencial entre uma opção de atualização e desenvolvimento da educação no contexto atual está em compreender uma intersubjetividade analógico-digital-virtual e uma virtualização da intersubjetividade. A cultura está antes nas pessoas que nas coisas e nos objetos. A identidade 
do sujeito se define na relação com o outro e não com as coisas e objetos. Essa compreensão é pressuposto para pensar relações éticas e políticas no todo da sociedade atual.

Uma educação pensada e organizada nas e pelas ferramentas comunicacionais tende a seguinte conclusão.

Para um tal paradigma, que instituí a comunicação como fundamento estrutural da subjetividade, toda a intersubjetividade equivaleria à comunicabilidade, e toda a comunicação a uma transferência de informações, sem maior atenção às expressóes sensíveis da experiência vivida. O corolário deste modelo é a consolidação da informática como "espírito" da sociedade contemporânea (SODRÉ, 2006, p. 65).

O horizonte de compreensão desse conjunto de argumentos é auscultar uma educação que esteja atualizada segundo a nova configuração antropológica e de capacidade de ação na configuração das relaçôes e organizaçôes da sociedade. A educação precisa estar numa dimensão de antecipação e não de retaguarda ou de reflexão que busca resolver os problemas da sociedade. Com isso, pensar ética e politicamente elementos que permitem uma globalização, uma comunicação, um desenvolvimento "propícios a facilitar a vida e proporcionar a felicidade aos homens". "Os novos instrumentos, pela sua própria natureza, abrem possibilidades para sua disseminação no corpo social, superado as clivagens socieconômicas preexistentes" (SANTOS, 2003, p. 164).

O quarto ponto é interrogar sobre o sentido, a finalidade, as relações éticas e políticas da educaçáo a partir da configuração do ser humano como hominis comunicator, do ser humano como ser na e pela comunicação e suas tecno-mídias. Assim, a educação pode ser pensada como base de toda a incorporação tecno-midiática na escola, em que não há uma tecnificação do operar pedagógico pelas tecnologias da comunicação.

Apresento esse a ser pensado em quatro questionamentos. O primeiro trata das tecnologias e sua informatização como configuração da organização de sociedade em todas as suas dimensóes. O ser humano tornou-se dependente e condicionado pelas tecnologias. Estas remodelaram as noçóes de espaço e tempo e as relaçôes humanas em particular e societais em geral. Para Pierre Lévy (1999, p. 37, "a revolução contemporânea das comunicaçôes, da qual a emergência do ciberespaço é a manifestação mais marcante, é apenas uma das dimensôes de uma mutação antropológica de grande amplitude". Essa emergência comunicacional está na condição da emergência do sensível como modo de ser do ser humano em substituição do modo de ser intelectualizado. A educação tem um grande desafio de pensar o sensível no seu modo de ser em termos de ensino e de aprendizagem e, este, ligado à revolução das comunicações e suas tecnologias. Toda e qualquer reflexão sobre o direcionamento da educação e formação "na cibercultura deve apoiar-se numa análise prévia da mutação contemporânea da relação com o saber" (LÉVY, 1999, p. 158).

O segundo questionamento está relacionado ao condicionamento das comunicaçôes e das possíveis mutação antropológicas, em que um "novo" ser humano está sendo significado existencialmente. E, com isso, a criação de valores, pressupostos, sentidos de estrutura e organizaçôes, relaçôes sociais e políticas que não parecem adequadas ao bem comum. $\mathrm{O}$ momento presente, segundo Lipovetsky, (2005) é de vazio como modo de ser: uma era do vazio. O direcionamento está lançado para uma nova época da humanidade, orientada pelas comunicaçôes e suas tecnologias. O sentido disso para o ser humano, suas relaçôes sociais, 
culturais, políticas e educacionais vai sendo formatada aos poucos. Pensar a educação nesse contexto de vazio de sentido e de nova configuração pelas comunicaçóes é uma das possibilidades da educação ser ativa na nova significação do ser humano e suas relaçóes.

O terceiro questionamento, na esteira argumentativa de Muniz Sodré, de que com na revolução contemporânea das comunicaçóes, dá-se o "advento de um provável novo paradigma de conhecimento, a que se poderia chamar de analógico-digital (SODRÉ, 2002, p. 92). Essa mudança paradigmática do conhecimento está ligada há uma mudança mais ampla no todo da sociedade como forma de organização e vida. A transformação e sua relativização "do paradigma dominante e as novas formas de organização do trabalho provocam alteraçóes importantes na relação pedagógica em todos os níveis de escolaridade, tanto nos modos de ensinar e apreender quanto nos conteúdos disciplinares" (SODRÉ, 2002, p. 96).

Essas exigências de uma mudança na educação pela forma de organização societal não podem ser pensadas e efetivadas com uma maquinação da escola, para satisfazer as novas relaçóes entre ciências e tecnologias, relaçôes da educação com as empresas e dos saberes técnicos da ordem apenas do trabalho. Essa maquinação significa também uma maquinação do humano. Por isso, é preciso pensar uma escolarização da máquina, como forma de novas formas de saber e aprendizagem, sem reduzir o saber à relação com as máquinas.

O quarto questionamento refere-se aos juízos de valor sobre a tecnificação, hipotetizando que a maquinação não é boa nem ruim em si mesma. $\mathrm{O}$ uso e o direcionamento que a ela se dá é que a torna ruim ou boa. Para Lévy (1994) a educação é imprescindível para o bom uso da máquina como ferramenta. "Isso é muito claro e, ao mesmo tempo, um desfio tremendo. As pessoas precisam apreender a fazer as coisas do jeito certo. É simples assim. É educação". "O problema não é o acesso, é a falta de capacidade em utilizar bem a Web” (LÉVY, 2005, p. 02). Sem educação, sem uma escolarização da máquina, como base dos usos das ferramentas, elas por si só podem se tornar obsoletas e sem nenhuma utilidade social e cultural. A capacidade de uma inteligência coletiva, de melhoria das condiçóes sociais dos povos, de "democracias direta e em grande escala" (LÉVY, 1994, p. 8), de uma ética baseada no respeito ao ser humano são possíveis na e pela educação, com uma qualificação e atualização com as novas ferramentas tecno-midiáticas que configuram uma nova antropologia compreendida como comunicacional num habitat midiático.

O último questionamento é sobre as narrativas que apresentam a no configuração de uma "nova ordem tecnológica" (FILHO e CASTRO, 2008, p. 15) como uma nova ordem dialógica. $\mathrm{Na}$ educação entendemos que se compreende como intersubjetividade analógico-digital-virtual. Pensar a educação em termos de intersubjetividade é superar o vazio como um modo de viver de uma era, que tem no individualismo contemporâneo sua base, instaurado numa segunda revolução individualista. Nessa ordem compreensiva educacional como intersubjetividade é possível pensar nova relaçóes éticas e políticas capazes de efetivar uma sociedade que resolva as questão da exclusão, da miséria, da dignidade dos seres humanos, da emancipação de todas as formas de atrofiamento da vida. A educaçáo pensada como intersubjetividade torna-se uma linguagem, uma cultura da educação, numa relação ética e política no todo das relaçôes e organizaçóes da sociedade. Para isso, a comunicaçáo precisa se emancipar de todos os seus limites, para ser o modo mais próprio de ser do ser humano, numa compreensão de si, dos outros e da sociedade em geral. 
Sem a pretensão de resolver esses questionamentos, mas buscar aprofundá-los para pensar com profundidade os desafios educacionais atuais. Compreendo que as possibilidades de uma educação ativa nas relaçóes éticas e políticas do presente se dá no âmbito da renovação do mundo na perspectiva do bem comum pelas novas gerações, "crescidas" dentro de computadores e celulares. A antecipaçáo pode ser entendida aqui como um pro-jetar-se a frente para que a vida seja vivida e o contexto construído segundo o modo de ser da educação como construção e formação do humano. Antecipar-se para não precisar ficar cavando trincheiras ou se defendendo sempre contra as ações que vão se incrustando, como a do mercado e da economia no presente. Por isso, ter na interpretação e compreensão antropológica do presente e de seus encaminhamentos projetivos para que e a educação possa ser condicionante e não simplesmente condicionada.

\section{Consideraçóes finais}

Não há como não causar certa estranheza se a expressão "estive pensando", comumente usada, for substituída pela expressão "estive comunicando". A primeira pressupõe uma ação individual que pode ser compreendida num diálogo, sendo típica do pensamento moderno que tem na subjetividade seu fundamento. Com a constituição do paradigma da linguagem em superação do moderno, a comunicaçáo se tornou o modo de ser de base. Esse novo paradigma, da linguagem, ultrapassou a dimensão de base das ciências humanas e exatas, para se tornar uma fonte de produtos de relação de troca, compra e venda num sistema econômico mercadológico globalizado. A comunicação não é mais apenas o modo de ser fundamental do ser humano, mas também da revolução tecnológica e industrial.

Não há como pensar a estrutura da sociedade atual sem a questão da comunicação. O homem é um ser comunicador em todas as suas dimensôes. E, dessa compreensão, do seu contexto, seus elementos organizadores, no todo da sociedade, pensar a educação em novas relaçôes éticas e políticas, para que a mesma possa antecipar-se e ser ativa na configuração dos elementos condicionantes da sociedade. Nessa tomada de decisão e posição a educação pode colaborar para uma sociedade que resolva os problemas da miserabilidade, da exclusão, do desrespeito às diferenças, da injustiça, de tudo aquilo que coloca milhóes de seres humanos na marginalidade atrofiante da vida que tem apenas um horizonte de morte organizada não-dada.

O papel da educação como espaço/tempo livre de aprendizagens que permitem o ingresso no mundo adulto passa hoje pela vivência dessa nova configuração antropológica nas e pelas tecno-mídias. É preciso escolarizá-las, como propões Sodré, para que não sejam simplesmente meios de manutenção e maior propagação da miserabilidade, da indiferença em todas as suas formas e da pobreza.

A intersubjetividade não é pressuposto e acontecência da educação. Enquanto o individualismo imperar, a educação vai estar na condição de serva, porque ela é relacional, dialógica, coletiva. Assim, ela se torna um gesto de amor ao mundo antes de ser amor a um sujeito que ingressa na instituição escolar. Mas, como o mundo é um modo de viver e, por isso, dinâmico e por se fazer constantemente, suas novas configurações precisam ser repensadas constantemente. Esse rever reflexivo tem como perspectiva a não natuzaralização de um modo apenas ou de uma forma cultural. 


\section{Referências}

ARENDT, Hannah. Entre passado e futuro. São Paulo: Editora Perspectiva, 1997.

BAUMAN, Zygmunt. Medo líquido. Rio de Janeiro: Zahar. 2008.

BAUMAN, Zygmunt. Modernidad líquida. Buenos Aires: Fondo de Cultura Econômica. 2002.

BAUMAN, Zygmunt. Modernidade e Ambivalência. Rio de Janeiro: Zahar. 1999.

BAUMAN, Zygmunt. Vida Líquida. Rio de Janeiro: Zahar. 2005.

BOUFLEUR, José Pedro. Pedagogia da Açáo Comunicativa. Ijui: Unijui, 1997.

LÉVY, Pierre. A ideografia dinâmica: para uma imaginaçáo artificial? Lisboa: Instituto Piaget, 1997.

LÉVY, Pierre. A inteligência coletiva: por uma antropologia do ciberespaço. 3. ed. São Paulo: Loyola, 2000.

LÉVY, Pierre. As tecnologias da inteligência: o futuro do pensamento na era da informática. 1. ed. Lisboa: Instituto Piaget, 1992.

LÉVY, Pierre. Cibercultura. São Paulo: Editora 34, 1999.

LÉVY, Pierre. L'intelligence collective. Pour une anthropologie du cyberespace. Paris: La Découverte, 1994.

LÉVY, Pierre. L'universel sans totalité. In: Magazine Littéraire. 1966-1996. La passion des idées, 1996.

LÉVY, Pierre. O que é o virtual? São Paulo: Editora 34, 1996.

LIPOVETSHY, Gilles. A Era do Vazio, ensaios sobre o individualismo contemporâneo. São Paulo: Manole, 2005.

MAFFESOLI, Michel. Elogio da Razão Sensível. Petrópolis: Vozes, 1998.

SÁ MARTINO, Luis. Estética da Comunicação: da consciência comunicativa ao "eu" digital. Petrópolis: Vozes, 2007.

SANTOS, Elisio e VARGAS, Heron (Orgs). Mutaçóes da cultura midiática. São Paulo: Paulinas, 2009.

SAVATER, Fernando. El valor de educar. Barcelona: Ariel, 1997.

SODRÈ, Muniz e PAIVA, Raquel. O império do Grotesco. Rio de Janeiro: Mauad, 2002.

SODRÉ, Muniz. Antropológica do Espelho, uma teoria da comunicaçáo linear e em rede. Petrópolis: Vozes, 2002.

SODRÉ, Muniz. As estratégias sensíveis: afeto, mídia e política. Petrópolis: Vozes, 2006. 
SODRÉ, Muniz. O monopólio da fala, função e linguagem da Televisão no Brasil. Petrópolis: Vozes, 1984.

SODRÉ, Muniz. Reinventando a Cultura. Rio de Janeiro: Vozes, 1997.

TOURAINE, Alain. Um novo paradigma para compreender o mundo de hoje. Petrópolis: Vozes, 2007. 